\title{
Método para a Determinação de Ácidos Fenólicos na Parede Celular de Forragens
}

\author{
Francisco Carlos Deschamps ${ }^{1}$, Luiz Pereira Ramos ${ }^{2}$
}

\begin{abstract}
RESUMO - Há fatores que limitam a digestão das forragens tropicais e estão associados à dinâmica dos ácidos fenólicos da parede celular. Os estudos destes compostos em forragens podem ser facilitados pela disponibilidade de métodos sensíveis que permitam o processamento de grande número de amostras. No presente trabalho, descreve-se um método para a determinação de ácidos fenólicos na parede celular de forragens, utilizando cromatografia líquida de alta eficiência (CLAE). Bagaço de cana, capim-elefante e folhas de mandioca foram utilizados como amostras experimentais. Para remover substâncias solúveis de baixa massa molecular, foram testados etanol $80 \%$ e o detergente neutro, determinando seus efeitos sobre a recuperação das moléculas e benefícios no perfil cromatográfico. Para a obtenção dos ácidos fenólicos livres, as amostras foram solubilizadas em $\mathrm{NaOH} 1 \mathrm{~mol} / \mathrm{L}, 20^{\circ} \mathrm{C}$ por 24 horas. O método proposto foi adequado para a determinação de ácidos fenólicos, apresentando grande sensibilidade e produtividade no laboratório. Para minimizar os efeitos negativos da formação de sal resultante da neutralização ácida do extrato alcalino, sugere-se a diluição da amostra ou a injeção de pequeno volume $(5 u \mathrm{~L})$ no aparelho. O efeito da utilização de solventes como etanol $80 \%$ ou detergente neutro é distinto sobre as amostras das gramíneas e leguminosas. A quantidade de extrativos nas folhas de mandioca foi superior a do bagaço de cana e capim-elefante. A concentração de ácidos fenólicos foi pouco alterada pela ação dos solventes, sendo maior nas amostras de bagaço de cana e capim-elefante, em relação às folhas de mandioca. O método apresentado constitui-se em uma importante ferramenta para o estudo dos ácidos fenólicos na parede celular de forragens tropicais.
\end{abstract}

Palavras-chave: ácido ferúlico, ácido p-cumárico, CLAE, lignina, parede celular vegetal

\section{Method for Phenolic Acid Determination in Forage Cell Wall}

\begin{abstract}
Factors that limit the digestion of tropical forages are associated to the dynamic of cell wall phenolic acids. The study of these compounds in forages may be facilitated by the availability of sensible methods that permit processing large amounts of samples. The present paper describes a method for determining phenolic acids in forage cell wall through high-performance liquid chromatography (HPLC). Sugar cane bagasse, elephant grass and cassava leaves were used as experimental samples. To remove soluble low molecular weight products, ethanol $80 \%$ and neutral detergent were essayed to determine their effects on the recovery of molecules and other benefits to chromatography profile. The sample solubilization with $\mathrm{NaOH} 1 \mathrm{~mol} / \mathrm{L}, 20^{\circ} \mathrm{C}$ for 24 hours, was used to obtain the free phenolic acids The method described proved appropriate showing great sensibility and lab productivity. To minimize the effects of salt formation as a consequence of acid neutralization, sample dilution and reduced injection volumes $(5 u \mathrm{~L})$ are suggested. The action of ethanol $80 \%$ and neutral detergent differ between grasses and legumes. The amount of extractives in cassava leaves was greater than in other materials. The method described in the present paper is an important tool to study phenolic acids in tropical forage cell wall.
\end{abstract}

Key Words: ferulic acid, HPLC, lignin, p-coumaric acid, vegetal cell wall

\section{Introdução}

A digestão da parede celular das plantas forrageiras apresenta-se intimamente associada a sua composição química. Dos componentes da parede celular, a lignina é considerada a que apresenta o maior efeito negativo sobre a digestão ruminal (Kamstra et al., 1958; Terry \& Tilley, 1964; Nascimento Jr., 1974; Jung \& Vogel, 1986; Reeves, 1987; Hatfield, 1993; Burns et al., 1997; Deschamps, 1999). Estes efeitos são mais pronunciados nas gramíneas tropicais, principalmente com o envelhecimento das plantas forrageiras. Deve ser considerado que a disponibilidade de energia luminosa nos trópicos permite elevadas taxas de crescimento das forrageiras, como parte da sua adaptação fisiológica (metabolismo-C4). Este elevado potencial de produção não pode ser adequadamente aproveitado, principalmente pelos efeitos negativos da deposição da lignina, resultantes da maturação fisiológica da planta.

Entretanto, parece que a concentração de lignina presente na parede celular das forragens não é

\footnotetext{
${ }^{1}$ Pesquisador-Doutor, EPAGRI-S/A/UNIVALI. Cx. Postal 277, 88.301-970, Itajaí, SC, Brasil. E.mail: xicodsc@hotmail.com

${ }^{2}$ Professor-Doutor, Depto. Química UFPr, Cx. Postal 19081, 81531-990, Curitiba, PR. Brasil. Bolsista do CNPq. E.mail: Iramos@quimica.ufpr.br
} 
suficiente para explicar determinadas variações na digestão de forragens ou parte das mesmas (Morrison et al., 1998; Deschamps, 1999). Entre outros, o arranjo da lignina e seus precursores com os demais componentes da parede celular pode ser responsabilizado por boa parte das limitações observadas na digestão das forragens. Deste modo, pouca relação se poderia esperar entre a composição da lignina como unidade polimérica e a digestão da parede celular das forragens. Assim, a concentração de seus precursores e principalmente a associação destes com os carboidratos constituintes da parede celular, desempenhariam então, um papel mais importante. Os ácidos fenólicos, especialmente p-cumárico e ferúlico, estão diretamente envolvidos na associação da lignina com as hemiceluloses (polioses) da parede celular. As principais formas de interação molecular estão bem estabelecidas e envolvem ligações éster e éter com os carboidratos e unidades condensadas da lignina (Jung \& Deetz, 1993).

Como método para diferenciar se os ácidos fenólicos estão ligados a outras moléculas na forma éster ou éter, tem sido proposta sua extração em condições diferenciadas de concentração de $\mathrm{NaOH}$ (Iiyama et al., 1990; Morrison III et al., 1993; Morrison et al., 1998). Assim, os ácidos fenólicos ligados na forma éster são extraídos em solução de $\mathrm{NaOH}$ (1 a 2 moles/L) em temperaturas brandas $\left(20^{\circ} \mathrm{C}\right)$. Condições mais severas $\left(\mathrm{NaOH} 4\right.$ moles $\left./ \mathrm{L}, 170^{\circ} \mathrm{C}\right)$, solubilizam fenóis totais, sendo a diferença entre totais e éster a quantidade de fenóis ligados na forma éter. Após o isolamento dos ácidos fenólicos, sua presença e quantificação dependem, então, da disponibilidade de métodos simples, de grande sensibilidade e produtividade no laboratório. Isto é especialmente importante no estudo das forrageiras, já que normalmente implica no processamento de grande número de amostras.

No presente trabalho foi otimizado um método para determinação de ácidos fenólicos em parede celular de forragens tropicais com a utilização da cromatografia líquida de alta eficiência (CLAE). O método baseou-se na sequência original de Hartley \& Buchan (1979), os quais propuseram a determinação simultânea de fenóis e aldeídos derivados da parede celular de plantas ou da matéria orgânica do solo.

\section{Materiais e Métodos}

O bagaço de cana foi obtido junto a uma Usina de Açúcar e Álcool localizada no município de Itajaí, SC
(Deschamps et al., 1996). As folhas de capim-elefante cv. Empasc-307-Testo (acesso IJ-7136) com 28 dias de crescimento e as de mandioca cv. Pernambucana com 133 dias de crescimento, foram obtidas junto à Epagri - Estação Experimental de Itajaí, SC (Deschamps \& Vetterle, 1997; Deschamps, 1999). Todas as amostras foram moídas em moinho tipo faca, dotado de peneira de $1 \mathrm{~mm}$.

A proteína bruta foi determinada em triplicata, adotando-se o método Kjeldahl - semi-micro (Silva, 1981).

Para a extração com etanol $80 \%, 3 \mathrm{~g}$ das amostras foram acondicionadas em saquinhos de nylon medindo $5 \times 7 \mathrm{~cm}$, com cerca de $45 \mathrm{um}$ de porosidade. Foram utilizadas três repetições para cada material tratado, sendo as amostras mantidas sob agitação em 1 litro da solução, durante duas horas em temperatura ambiente. Após este período, as amostras foram lavadas em água corrente e deixadas para secar em estufa $60^{\circ} \mathrm{C}$. $\mathrm{O}$ tratamento das amostras com detergente neutro (DN) também foi realizado em triplicata no mesmo sistema de acondicionamento descrito anteriormente. As amostras foram então submetidas à extração em detergente neutro por 40 minutos em autoclave à $120^{\circ} \mathrm{C}$ (Deschamps, 1999).

Para a solubilização dos ácidos fenólicos, $50 \mathrm{mg}$ de amostra foram submetidas à extração em um tubo de ensaio, com $5 \mathrm{~mL}$ de $\mathrm{NaOH} 1$ moles/L por 24 horas em uma incubadora a $20^{\circ} \mathrm{C}$. Em seguida, o material foi filtrado em filtro de fibra de vidro e lavado com água Mille-Q, sendo o filtrado acidificado para $\mathrm{pH} 2,5$ com a adição de $0,7 \mathrm{~mL}$ de uma solução de HCL: $\mathrm{H}_{2} \mathrm{O}$ (1:1). O volume final foi ajustado para $10 \mathrm{~mL}$ com água, sendo retirados $2 \mathrm{~mL}$ para posterior análise. Após uma noite em geladeira, o material foi centrifugado em centrifuga tipo Eppendorf (13.000 rpm) por 5 minutos, sendo deixado em congelador até o momento da análise. Após o descongelamento para a injeção no cromatógrafo, as amostras foram novamente centrifugadas (13.000 rpm por 5 minutos). Cerca de $0,5 \mathrm{~mL}$ foi então transferido para os frascos do injetor automático do HPLC. O volume de injeção foi de $5 u$ L.

As determinações foram conduzidas em um equipamento da marca Shimadzu, modelo LC10-VP, dotado de bomba para gradiente quaternário, injetor automático com suporte de amostras termostatizado $\left(10^{\circ} \mathrm{C}\right)$, forno de coluna $\left(40^{\circ} \mathrm{C}\right)$ e detector de absorção no Ultra Violeta (ajustado para $225 \mathrm{~nm}$ ). O sistema é gerenciado por uma estação de trabalho dotada de software específico. A coluna utilizada foi

R. Bras. Zootec., v.31, n.4, p.1634-1639, 2002 
a Shim-pack-CLC-ODS(M) com $25 \mathrm{~cm}$ de comprimento, 4,6mm de diâmetro, preenchida com octadecil - C18 como fase estacionária (5 um de diâmetro da partícula e $100 \mathrm{~A}^{\mathrm{o}}$ de diâmetro do poro). Embora recomendado, no presente trabalho não foi utilizada uma pré-coluna para retenção de eventuais impurezas. A fase móvel otimizada para o trabalho foi de água:ácido acético:n-butanol (350:1:10). O fluxo utilizado foi de 1,0 mL por minuto. Fluxos maiores ou menores podem ser utilizados desde que se observe os limites de pressão da coluna e da bomba. A escolha pelo regime de fluxo do sistema será determinante sobre o tempo de retenção das moléculas em estudo. Para o fluxo adotado no presente método, a pressão média atingida foi de $130 \mathrm{kgf}$.

O delineamento experimental foi inteiramente casualizado com seis repetições de cada amostra, utilizando-se, para a comparação entre as médias, o teste de Duncan, a 5\% de probabilidade do erro.

\section{Resultados e Discussão}

A determinação de ácidos fenólicos em amostras de forragens tropicais pode oferecer informações importantes para a compreensão das limitações envolvidas na digestão ruminal da parede celular de tais espécies. O método discutido neste trabalho constitui uma ferramenta adicional para a determinação dos principais ácidos fenólicos envolvidos na lignificação e na interligação da lignina com os carboidratos da parede celular vegetal.

O perfil cromatográfico dos padrões utilizados no presente método está apresentado na Figura 1. Pode-se observar a perfeita separação de todos os compostos, em especial das formas isoméricas do ácido cumárico (orto, meta e para).

Ainda na Figura 1, encontram-se os perfis cromatográficos para amostras de bagaço de cana e capim-elefante, evidenciando os picos referentes aos ácidos p-cumárico e ferúlico. Observando a altura dos picos é possível visualizar as diferentes concentrações e relações molares dos ácidos fenólicos presentes em cada material. A extensão da corrida cromatográfica até 45 minutos serve para demonstrar que nas condições experimentais, apenas os ácidos p-cumárico e ferúlico são detectados. Cabe ressaltar que a presente determinação foi realizada a partir de uma extração branda destes ácidos fenólicos, representando formas de ligação éster conforme descrito por Iiyama et al. (1990); Morrison III et al.

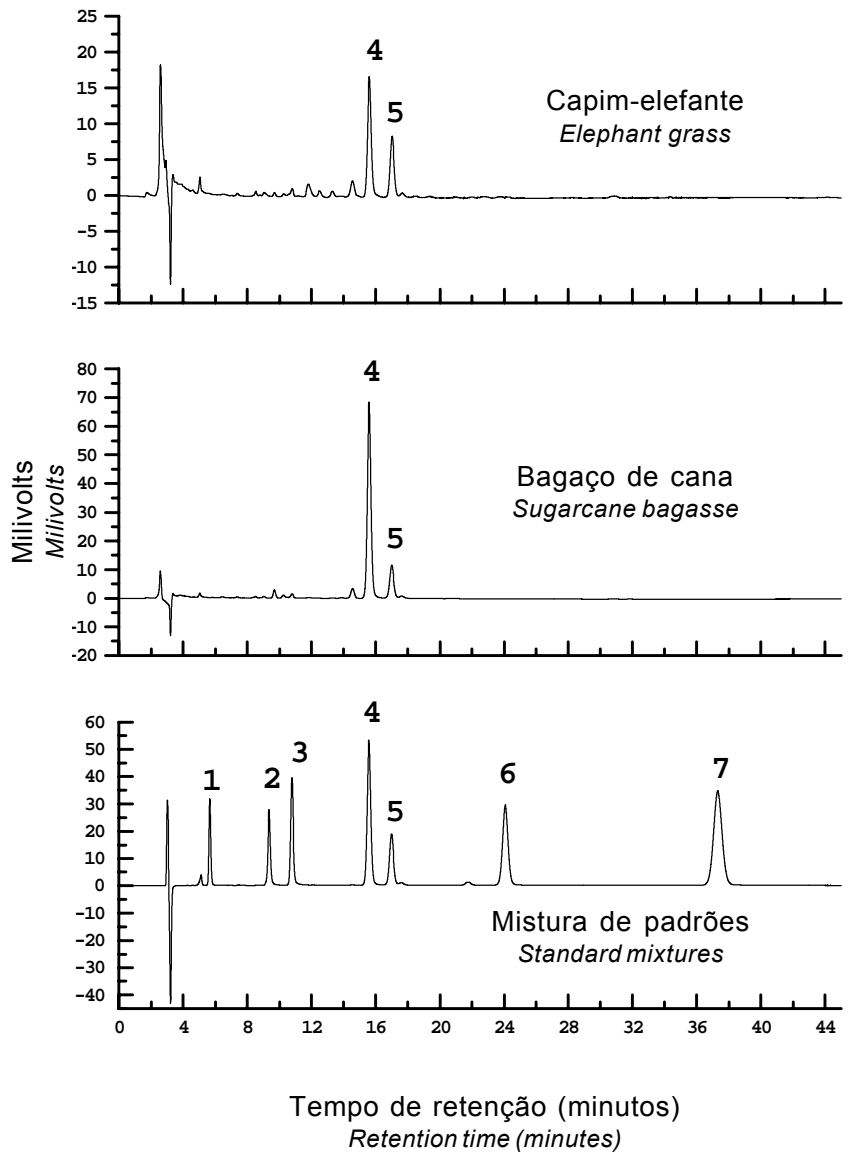

Figura 1 - Perfil cromatográfico para uma mistura de padrões de ácidos fenólicos e das amostras de capim-elefante e bagaço de cana. Os padrões utilizados foram Catequina(1), ácido cafeico(2), vanilina(3), ácido p-cumárico(4), ácido ferúlico(5), ácido $m$-cumárico(6) e ácido o-cumárico(7).

Figure 1 - Chromatographic profile of phenolic acid mixture standards, elephant grass and sugacane bagasse samples. The standards utilized were catechin(1), caffeic acid(2), vanilin(3), p-coumaric acid(4), ferulic acid(5), m-coumaric acid(6) o-coumaric $\operatorname{acid}(7)$.

(1993) e Morrison et al. (1998). É possível que nas condições mais severas de extração ( $\mathrm{NaOH} 4$ moles/L, $170^{\circ} \mathrm{C}$, por duas horas), outros derivados do complexo lignina ou lignina/carboidratos possam ser detectados. Dessa forma, é recomendável que o tempo de corrida para amostras oriundas desta nova condição de extração mais severa, seja inicialmente explorado em corridas de 45 a 60 minutos. Em função do perfil cromatográfico apresentado pelas amostras analisadas neste estudo, o tempo da corrida foi fixado, então, em 22 minutos. 
O tratamento das amostras com álcali e posterior acidificação geram apreciáveis quantidades de sal. Embora não se tenha observado alterações nas determinações cromatográficas, é importante considerar alguns cuidados, com vistas a preservar a integridade da coluna cromatográfica. Como as amostras são analisadas sem outras purificações ou derivatizações, deve-se ter cuidado com o volume a ser injetado no sistema. Neste sentido, o volume de injeção de $5 u$ L utilizado, foi suficiente para a determinação das moléculas de interesse (Figura 2 e Tabela 1). Este volume foi, portanto, bastante inferior aos $40 u \mathrm{~L}$ utilizados por Hartley \& Buchan (1979). Para amenizar ainda mais este efeito, pode-se diluir as amostras quando do processo de extração dos ácidos fenólicos.

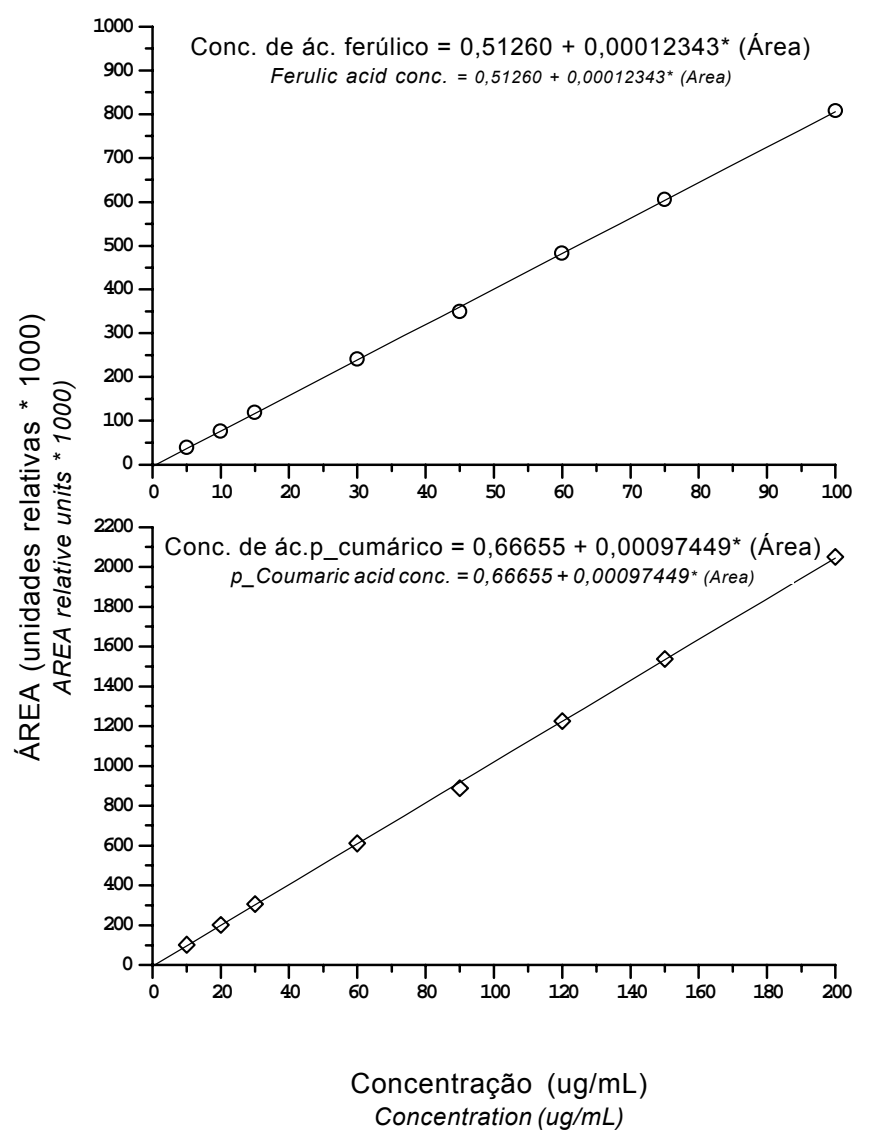

Figura 2 - Curva de calibração utilizada para determinação da concentração dos ácidos p-cumárico e ferúlico nas amostras extraídas com solução $1 \mathrm{~mol} / \mathrm{L}$ de $\mathrm{NaOH}$.

Figure 2 - Calibration curve utilized to determine the concentration of p-coumaric and ferulic acid in samples extracted with $\mathrm{NaOH}-1 \mathrm{~mol} / \mathrm{L}$.
Entretanto, isto depende de um estudo prévio para a determinação da concentração de ácidos fenólicos nas amostras em análise. No presente caso, as amostras de bagaço de cana e mesmo de capim-elefante poderiam ser ainda diluídas como forma de reduzir o aporte de sal sobre a coluna. Isto implicaria na aplicação do fator de diluição para a determinação da concentração final, ou na adequação da curva de calibração. Já no caso das amostras de folha de mandioca, a diluição não poderia ser aplicada (Tabela 1). Neste caso, aumentar a quantidade de amostra a ser extraída para $100 \mathrm{mg}$ por exemplo, poderia ser uma saída interessante para aumentar a quantidade de ácidos fenólicos no sistema sem alterar o aporte de sal.

A natureza química e anatômica da parede celular das gramíneas e leguminosas tropicais são distintas (Wilson, 1993). Isto deve ser considerado quando do estabelecimento de um protocolo de análise de ácidos fenólicos para este tipo de material, como ficou demonstrado no trabalho (Tabela 1). Neste caso, o pré-tratamento das amostras com etanol $80 \%$ ou detergente neutro apresenta alguns aspectos interessantes. O tratamento com detergente neutro é mais efetivo $(\mathrm{P}<0,05)$ na remoção de substâncias de menor massa molecular do que o observado com etanol $80 \%$ (Tabela 1). A natureza exata destes extratos não foi avaliada no presente estudo, mas em geral, pode-se considerar que o etanol solubiliza lipídeos e pigmentos, além de outras substâncias que fazem parte do conteúdo celular. Já o detergente neutro tende a solubilizar proteínas, gordura e carboidratos solúveis, pectina e outros compostos solúveis em água (Van Soest, 1967). A capacidade de remoção de compostos nitrogenados, aqui expressos como proteína bruta (PB), foi efetivo para o bagaço de cana e capim-elefante, mas não se alterou nas amostras de folhas de mandioca (Tabela 1). Comportamento inverso ocorre com os ácidos fenólicos nas amostras de folha de mandioca. Em parte, isto evidencia que os compostos nitrogenados são de natureza distinta, sendo sua extração ou solubilização, diferenciada em gramíneas e leguminosas. Já a resistência na remoção destes compostos nas folhas de mandioca, pode também estar relacionada à presença de outros compostos, como os chamados taninos condensados (Reed et al., 1982). Também poderia ser considerado o fato de os compostos nitrogenados nas gramíneas estarem em uma forma mais solúvel, enquanto nas leguminosas se apresentarem na forma de proteínas. Outro fenômeno que deve ainda ser

R. Bras. Zootec., v.31, n.4, p.1634-1639, 2002 
considerado é a interligação destes compostos nitrogenados com outras estruturas da parede celular como lignina, celulose e hemicelulose, tornando-os mais resistentes a extração.

A presença dos ácidos fenólicos está restrita à parede celular, sendo pouco provável que se encontre ácido p-cumárico e ferúlico livres nos extrativos. Entretanto, seria possível esperar que a ação dos extratores ou solventes, pudesse solubilizar parte dos ácidos fenólicos presentes na parede celular. Isto não foi observado no presente trabalho para as gramíneas (bagaço de cana e capim-elefante). Nas folhas de mandioca é que se observa a redução na concentração dos ácidos como resultado do aumento da ação dos extratores (Tabela 1). De qualquer forma, a concentração destes ácidos na amostra pode ser considerada pequena em relação ao bagaço e ao capim-elefante. A matéria seca, perdida pela ação de extratores, pode também, em parte, estar relacionada a perda de partículas finas resultantes da moagem das amostras.

A adoção de procedimentos de pré-tratamento das amostras com vistas a remover substâncias de baixa massa molecular, parece não alterar a concentração de ácidos fenólicos de amostras de gramíneas. Cuidados adicionais poderiam ser tomados com relação às leguminosas. A adoção do pré-tratamento é uma prerrogativa do pesquisador de acordo com os objetivos do seu estudo. O que ficou demonstrado no presente trabalho é que a ação dos solventes é diferenciada sobre as amostras de diferentes origens.

A concentração de ácidos fenólicos na parede celular das forragens pode contribuir para o entendimento das limitações de digestão que muitas espécies tropicais apresentam. Tem-se postulado que nas plantas jovens, os complexos éster/ácido ferúlico se constituem em sítios iniciadores para a polimerização da lignina (Morrison et al., 1998). Isto porque, com o envelhecimento dos tecidos, a quantidade de ferulatos éster-ligados tende a se manter, enquanto aqueles éter-ligados são incrementados (Morrison et al., 1998; Jung et al., 1998).

A interligação do ácido ferúlico com a arabinose e lignina cria obstáculos para a degradação dos polissacarídeos da parede celular das forragens

Tabela 1 - Efeitos da utilização do etanol e detergente neutro nos teores de proteína bruta e ácidos fenólicos do bagaço de cana, capim-elefante e folha de mandioca

Table 1 - Effect of ethanol and neutral detergent extration on crude protein and phenolic acids contents of sugarcane bagasse, elephant grass and cassava leaves

\begin{tabular}{|c|c|c|c|c|}
\hline $\begin{array}{l}\text { Amostras } \\
\text { Samples }\end{array}$ & $\begin{array}{l}\text { Extrativos }(\%) \\
\text { Extractives (\%) }\end{array}$ & $\begin{array}{c}\text { Proteína bruta }(\%) \\
\text { Crude Protein }(\%) \\
\text { p-coumaric acid } \\
\text { ug/mg/dry matter }\end{array}$ & $\begin{array}{c}\text { Ácido p-cumárico } \\
\text { ug/mg/mat. seca } \\
\text { Ferulic acid } \\
\text { ug/mg/dry matter }\end{array}$ & $\begin{array}{l}\text { Ácido ferúlico } \\
\mathrm{ug} / \mathrm{mg} / \mathrm{mat} \text {. seca }\end{array}$ \\
\hline $\begin{array}{l}\text { Bagaço de cana - sem extrair } \\
\text { Sugarcane bagasse - no extraction }\end{array}$ & - & $2,47 \pm 0,57^{\mathrm{a}}$ & $18,98 \pm 0,99^{a}$ & $4,56 \pm 0,23^{b}$ \\
\hline $\begin{array}{l}\text { Bagaço de cana - EtOH }{ }^{1 /} \\
\text { Sugarcane bagasse - Ethanol extracted }\end{array}$ & $11,3 \pm 0,33^{b}$ & $0,85 \pm 0,07^{b}$ & $19,74 \pm 0,60^{\mathrm{a}}$ & $4,90 \pm 0,19^{b}$ \\
\hline $\begin{array}{l}\text { Bagaço de cana - FDN }{ }^{2 /} \\
\text { Sugarcane bagasse - NDF extracted }\end{array}$ & $17,5 \pm 0,65^{a}$ & $0,37 \pm 0,01^{\mathrm{c}}$ & $20,33 \pm 0,82^{a}$ & $5,36 \pm 0,24^{\mathrm{a}}$ \\
\hline $\begin{array}{l}\text { Capim-elefante - sem extrair } \\
\text { Elephant grass - no extraction }\end{array}$ & 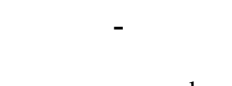 & $13,19 \pm 0,52^{\mathrm{a}}$ & $5,87 \pm 0,17^{\mathrm{a}}$ & $3,96 \pm 0,12^{b}$ \\
\hline $\begin{array}{l}\text { Capim-elefante - } \text { EtOH }^{1 /} \\
\text { Elephant grass - Ethanol extracted }\end{array}$ & $20,4 \pm 0,35^{\mathrm{b}}$ & $11,70 \pm 0,10^{b}$ & $6,32 \pm 0,36^{\mathrm{a}}$ & $4,32 \pm 0,25^{\mathrm{a}}$ \\
\hline $\begin{array}{l}\text { Capim-elefante - FDN }{ }^{2 /} \\
\text { Elephant grass - NDF extracted }\end{array}$ & $28,6 \pm 0,13^{a}$ & $5,74 \pm 0,35^{\mathrm{c}}$ & $6,35 \pm 0,39^{a}$ & $4,49 \pm 0,31^{\mathrm{a}}$ \\
\hline $\begin{array}{l}\text { Folha de mandioca - sem extrair } \\
\text { Cassava leaf - no extraction }\end{array}$ & - & $18,56 \pm 0,71^{b}$ & $0,64 \pm 0,02^{\mathrm{a}}$ & $0,79 \pm 0,03^{a}$ \\
\hline $\begin{array}{l}\text { Folha de mandioca - } \mathrm{EtOH}^{1 /} \\
\text { Cassava leaf - Ethanol extracted }\end{array}$ & $28,7 \pm 1,05^{b}$ & $20,10 \pm 0,26^{\mathrm{a}}$ & $0,35 \pm 0,03^{b}$ & $0,37 \pm 0,04^{b}$ \\
\hline $\begin{array}{l}\text { Folha de mandioca - FDN }{ }^{2 /} \\
\text { Cassava leaf - NDF extracted }\end{array}$ & $47,5 \pm 0,61^{\mathrm{a}}$ & $19,18 \pm 0,54^{\mathrm{b}}$ & $0,33 \pm 0,03^{b}$ & $0,27 \pm 0,03^{\mathrm{c}}$ \\
\hline
\end{tabular}

R. Bras. Zootec., v.31, n.4, p.1634-1639, 2002 
(Grabber et al., 1998). As diversas formas pelas quais estes ácidos fenólicos podem se associar às hemiceluloses, ou mesmo serem incorporados à lignina, constitui-se na grande barreira para a digestão dos materiais (Grabber et al., 1998; Lu \& Ralph, 1999).

No presente trabalho, pode-se observar que a concentração dos ácidos fenólicos foi bastante distinta para os três materiais estudados (Tabela 1). A concentração média de ácido ferúlico não foi muito diferente entre bagaço de cana e capim-elefante. Entretanto, a concentração de ácido p-cumárico foi bastante superior no bagaço de cana. Isto representa um indicativo para a reduzida digestão que o bagaço apresenta (Deschamps et al., 1996). Já nas folhas de mandioca, a baixa concentração de ácidos fenólicos, associada a natureza de seus tecidos, sugerem outros fatores limitantes para a sua digestão (Reed et al, 1992).

\section{Conclusões}

O método proposto no presente trabalho pode ser considerado simples e adequado para a determinação de ácidos fenólicos na parede celular de forragens tropicais, permitindo o processamento de um grande número de amostras. As gramíneas e leguminosas apresentam distintas concentrações de ácidos fenólicos, sendo superior nas primeiras. A ação de solventes sobre as amostras é distinta, já que o detergente neutro solubiliza maior quantidade de substâncias de baixa massa molecular em comparação ao etanol 80\%. Para a determinação de ácidos fenólicos em amostras de forragens, o uso de solventes como etanol $80 \%$ ou detergente neutro pode ser dispensado.

\section{Literatura Citada}

BURNS, J.C.; POND, K.R.; FISHER, D.S. et al. Changes in forages quality, ingestive mastigation and digesta kinetics resulting from switchgrass maturity. Journal of Animal Science, v.75, p.1368-1379, 1997.

DESCHAMPS, F.C. Implicações do período de crescimento na composição química e digestão dos tecidos de cultivares de capim-elefante. Revista Brasileira de Zootecnia, v.28, n.6, p.1358-1369, 1999.

DESCHAMPS, F.C.; VETTERLE, C.P. Perfil fenológico da mandioca (Manihot esculenta Crantz) cv. Pernambucana. In: REUNIÃO ANUAL DA SOCIEDADE BRASILEIRA DE ZOOTECNIA, 34., 1997, Juiz de Fora. Anais... Juiz de Fora: Sociedade Brasileira de Zootecnia, 1997. p.89-91.

DESCHAMPS, F.C.; RAMOS, L.P.; FONTANA, J.D. Pretreatment of sugarcane bagasse for enhanced ruminal digestion. Applied Biochemistry and Biotechnology, v.57/58, p.171-182, 1996.

GRABBER, J.H.; RALPH, J.; HATFIELD, R.D. Ferulate crosslink limit the enzymatic degradation of synthetically lignified primary walls of maize. Journal of Agricultural and Food
Chemistry, v.46, p.2609-2614, 1998.

HARTLEY, R.D.; BUCHAN, H. High-performance liquid chrometography of phenolic acids and aldehydes derived from plans or from the decomposition of organic matter in soil. Journal of Chromatography, v.180, p.139-143, 1979.

HATFIELD, R.D. Cell wall polysaccharides interaction and degradability. In: JUNG, H.G.; BUXTON, D.R.; HATFIELD, R.D. et al. (Eds.) Forage cell wall structure and digestibility. Madison: ASA/CSSA/SSSA, 1993. p.285-313.

IIYAMA, K.; LAM, T.B.T.; STONE, B.A. Phenolic acid bridges between polysaccharides and lignin in wheat internodes. Phytochemistry, v.29, p.733-737, 1990.

JUNG, H.G.; DEETZ,D.A. Cell wall lignification and degradability. In: JUNG, H.G.; BUXTON, D.R.; HATFIELD, R.D. et al. (Eds.) Forage cell wall structure and digestibility. Madison: ASA/CSSA/SSSA, 1993. p.315-346.

JUNG, H.G.; VOGEL, K.P. Influence of lignin on digestibility of forage cell wall material. Journal of Animal Science, v.62, p.1703-1712, 1986.

JUNG, H.G.; MORRISON, T.A.; BUXTON, D.R. Degradability of cell wall polysaccharides in maize internodes during stalk development. Crop Science, v.38, p.1047-1051, 1998.

KAMSTRA, L.D.; MOXON, A.L.; BENTLEY, O.G. The effect of stage af maturity and lignification on the digestion of cellulose in foage plants by rumen microorganisms in vitro. Journal of Animal Science, v.17, p.199-208, 1958.

LU, F.; RALPH, J. Detection and determination of $p \_$coumaroylated units in lignins. Journal of Agricultural and Food Chemistry, v.47, p.1988-1992, 1999.

MORRISON, T.A.; JUNG, H.G.; BUXTON, D.R. et al. Cell wall composition of maize internode of varying maturity. Crop Science, v.38, p.455-460, 1998.

MORRISON-III, W.H.; AKIN, D.E.; HIMMELSBACH, D.S. et al. Investigation of the éster and ether-linked phenolic constituents of cell wall types of normal and brown midrib pearl millet using chemical isolation, microspectrophotometry and ${ }^{13} \mathrm{C}-\mathrm{NMR}$ spectroscopy. Journal of Science Food Agriculture, v.63, p.329-337, 1993.

NASCIMENTO Jr., D. Comentários sobre métodos químicos para avaliação de forragens. Revista Brasileira de Zootecnia, v.3, p.233-244, 1974.

REDD, J.D.; McDOWELL, R.E.; Van SOEST, P.J. et al. Condensed tannins: A factor limiting the use of cassava forage. Journal of Science Food Agriculture, v.33, p.213$220,1982$.

REEVES, J.B. Lignin and fiber composition changes in forages over a growing season and their effects on in vitro digestibility. Journal of Dairy Science, v.70, p.1583-1594, 1987.

SILVA, J.D. Análise de alimentos (Métodos químicos e biológicos). Viçosa, MG: Universidade Federal de Viçosa, 1981. 166p.

TERRY, R.A.; TILLEY, J.M.A. The indigestibility of the leaves and stems of perennial ryegrass, cocksfoot, timothy, tall fescue, lucerne and sainfoin as measured by in vitro procedure. Journal British Grassland Society, v.19, p.362-372, 1964.

VAN SOEST, P.J. Development of a comphrehensive system of feed analysis and its applications to forages. Journal of Animal Science, v.26, p.119-128, 1967.

WILSON, J.R. Organization of forage plant tissues. In: JUNG, H.G; BUXTON, D.R.; HATFIELD, R.D. et al. (Eds.) Forage cell wall structure and digestibility. Madison: ASA/ CSSA/SSSA, 1993. p.1-32.

Recebido em: 09/08/01 Aceito em: 27/02/02

R. Bras. Zootec., v.31, n.4, p.1634-1639, 2002 